\title{
BMJ Open Physical frailty and health-related quality of life among Chinese rural older adults: a moderated mediation analysis of physical disability and physical activity
} Wenting Hao (D) , ${ }^{1}$ Jie Li, ${ }^{1}$ Peipei Fu, ${ }^{1}$ Dan Zhao, ${ }^{1}$ Zhengyue Jing, ${ }^{1}$ Yi Wang, ${ }^{1}$
Caiting Yu

To cite: Hao W, Li J, Fu P, et al. Physical frailty and health-related quality of life among Chinese rural older adults: a moderated mediation analysis of physical disability and physical activity. BMJ Open 2021;11:e042496. doi:10.1136/ bmjopen-2020-042496

- Prepublication history for this paper is available online. To view these files, please visit the journal online (http://dx.doi. org/10.1136/bmjopen-2020042496).

Received 07 July 2020 Revised 07 December 2020 Accepted 15 December 2020

Check for updates

(c) Author(s) (or their employer(s)) 2021. Re-use permitted under CC BY-NC. No commercial re-use. See rights and permissions. Published by BMJ.

${ }^{1}$ Centre for Health Management and Policy Research,School of Public Health, Cheeloo College of Medicine, Shandong University, Jinan, Shandong, China ${ }^{2} \mathrm{NHC}$ Key Lab of Health Economics and Policy Research, Shandong University, Jinan, Shandong, China

Correspondence to

Professor Chengchao Zhou;

zhouchengchao@sdu.edu.cn

\section{ABSTRACT}

Objectives The purpose of this study is to explore the mediating effect of physical disability as well as the role of physical activity (PA) as a moderator in the relationship between physical frailty and health-related quality of life (HRQLL) among rural older adults in China.

Design Cross-sectional analysis.

Setting Rural households in Shandong of China (Rushan, Qufu, Laolin).

Participants and methods A survey was conducted among 3243 rural older adults. The data were collected using questionnaires measuring physical frailty, physical disability, HRQoL and PA. Bootstrap analyses were employed to explore the mediating effect of physical disability and also the moderating role of PA on physical frailty and $H R Q D L$.

Results After controlling for age and education, physical disability partially mediated the effect of physical frailty on HRQOL (indirect effect $=-0.143,95 \% \mathrm{Cl}-0.175$ to -0.113 ), with the mediating effect accounting for $33.71 \%$ of the total effect. PA moderated the relationship between physical frailty and physical disability as well as the relationship between physical disability and HRQoL. Specifically, the interaction term between physical frailty and PA significantly predicted physical disability $(\beta=-0.120, t=-7.058, p<0.001)$, and the interaction term between physical disability and PA also had a significant predictive effect on HRQDL ( $\beta=0.115, t=6.104, p<0.001)$. Conclusions PA appears to moderate the indirect effect of physical disability on the association between physical frailty and $\mathrm{HRQOL}$. This study provides support for potential mechanisms in the association between physical frailty and $\mathrm{HRQOL}$. Encouraging rural older adults to increase PA appropriately might improve HRQoL for older adults with physical frailty and physical disability problems.

\section{INTRODUCTION}

Population ageing has become a global social problem. As one of the world's most ageing countries, China had 249 million people aged over 60 years in 2018, accounting for $17.9 \%$ of the total population. ${ }^{1}$ It is predicted that
Strengths and limitations of this study

- This is the first study to investigate the moderating and mediating factors of the relationship between physical frailty and health-related quality of life (HRQLL) among older adults in rural China.

- Moderated mediation model was used to explore the potential effect of physical disability and physical activity.

- Cross-sectional data could not provide strong evidence of causation and may result in biased estimates of mediation effects.

- Only two control variables were included in this study, and more confounding factors will be included to verify our results in the future.

- More potential mechanisms related to physical frailty and HRQoL among older adults need to be explored by using longitudinal data in the future.

by 2050 , older adults over 60 will account for more than $35.1 \%$ of the total population. ${ }^{2}$ With the increasing ageing population and the extension of life expectancy, improving health-related quality of life (HRQoL) of older adults is an important public health issue. HRQoL is a predictive factor of mortality in older adults. ${ }^{3}$ Compared with urban older adults, the HRQoL of rural older adults is worse,${ }^{45}$ which needs more attention.

Physical frailty is a medical syndrome caused by a variety of aetiologies and causes, which is characterised by a decline in physical strength, endurance and decreased physiological function. ${ }^{6}$ With the increase of age, the risk of physical frailty increases. ${ }^{7}$ Frailty may lead to negative health consequences, including falls, reduced activity, reduced independence, frequent hospitalisation and disability. ${ }^{8}$ These adverse outcomes resulted in a decline in the quality of life of older 
adults. Previous cross-sectional and longitudinal studies have shown that frailty was negatively associated with HRQoL, ${ }^{9-11}$ and frail older adults reported worse HRQoL than those who were not frail. ${ }^{12}$ Although the association between physical frailty and quality of life has been confirmed, the underlying mechanism remains unclear.

The prevalence of physical disability is high among frail older adults. ${ }^{13}{ }^{14}$ Some studies showed that physical frailty was closely related to disability ${ }^{15}{ }^{16}$ and might be the precursor and cause of disability. ${ }^{17} \mathrm{~A}$ national longitudinal study of 7439 people over 65 in the USA showed that frailty was a strong predictor of disability. ${ }^{18} \mathrm{~A}$ prospective 2-year cohort study in Japan also showed that frailty and prophase of frailty increased the risk of disability. ${ }^{19}$ These findings suggest that physical frailty is associated with disability in older adults. Studies have also demonstrated that the quality of life worsened as the degree of disability increased, and the more severe the disability, the worse the quality of life..$^{20}$ Compared with non-disabled older adults, disabled older adults are more prone to falls, depression, anxiety, and so on, and their HRQoL was significantly reduced. Therefore, we speculate that frailty may have an indirect effect on individual's HRQoL through the mediating effect of physical disability.

Physical frailty is considered to be reversible and preventable. ${ }^{21}$ Physical activity(PA) is a key factor of reverse and prevent frailty in older adults. ${ }^{22}$ Studies have found that PA moderated the relationship between chronic illness and functional limitations and moderated functional disability and body function. ${ }^{23}{ }^{24} \mathrm{PA}$ can alleviate the decline of physical function in older adults and has a beneficial effect on functional limitations, physical frailty, disability and quality of life in older adults. ${ }^{25-27}$ Studies indicated the positive effect of PA on reducing adverse events caused by frailty in older people. Performing a PA of moderate to vigorous intensity would improve physical frailty and prevent the occurrence of disability when compared with the performance of a PA of low intensity, ultimately promote older adults' quality of life. ${ }^{28-30}$ Therefore, PA may moderate the direct and indirect relationships between physical frailty and HRQoL through physical disability as a mediator.

In the present study, we used a cross-sectional study to examine the relationship between physical frailty and HRQoL, focusing on the mediating role of physical disability and the moderating role of PA in the relationship between physical frailty and HRQoL. The conceptual framework of the moderated mediation model is shown in figure 1.

\section{METHODS}

\section{Design and sample}

This study was conducted from May to June 2019 in Shandong province, China. A multistage stratified cluster sampling method was used to select participants, which was described in detail in a paper we have previously published. ${ }^{31}$ Three rural counties (Qufu, Laoling and

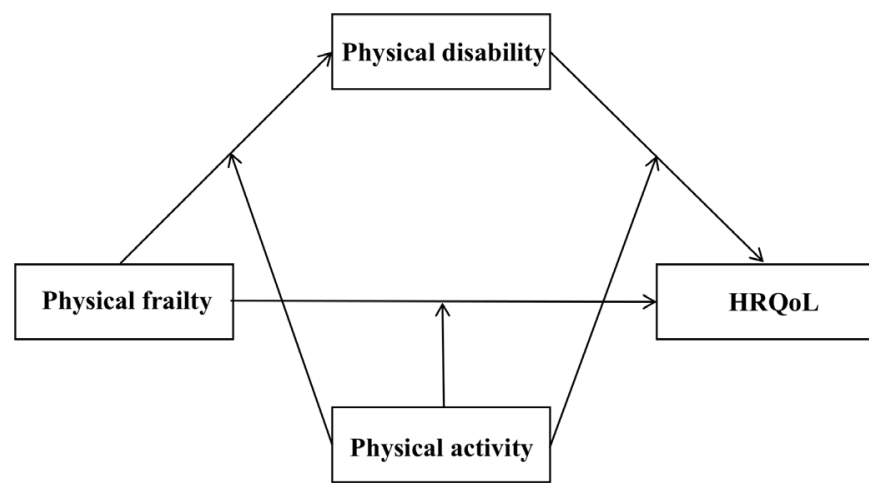

Figure 1 The conceptual framework of the moderated mediation model. HRQoL, health-related quality of life.

Rushan) were selected according to the gross domestic product (GDP) per capita (2018) in Shandong. Within each selected county, five townships were randomly selected. Then, four villages were selected from each selected townships and the elderly aged 60 years old and above were randomly selected from sample villages. All participants completed the questionnaire independently. A total of 3600 respondents were recruited from 60 villages and 15 townships in three rural counties in Shandong province, of whom 3243 completed the entire survey, with a response rate of $90.05 \%$.

\section{Variables and measurement}

\section{Independent variable}

Physical frailty was measured by frailty phenotype. ${ }^{32}$ The scale is a widely used frailty screening scale with good reliability and validity. ${ }^{33}$ Frailty was defined based on the following five aspects: weight loss, exhaustion, low PA level, slowness and weakness. (1) Weight loss: in the past 1 year, participants' body mass index (BMI) decreased by $>5.0 \%$ (except for personal deliberate weight loss), (2) exhaustion: using the Centre for Epidemiological StudiesDepression $^{35}$ : 'How often in the last week did you feel this way?" (a) I could not get going and (b) I felt everything I did was an effort. Either of the above two questions that participants answered 3 4 days and most of the time was considered exhaustion, (3) low PA level: according to the International Physical Activity Questionnaire-Short Form (IPAQ-SF), ${ }^{36} 37$ we used standard algorithms to calculate the Kcals consumed per week. The criterion is adjusted according to gender. Male: $<383 \mathrm{Kcals} /$ week is a decrease in PA, while female: $<270 \mathrm{Kcals} /$ week is a decrease in PA, (4) slowness: slowness was assessed via walking speed at $15 \mathrm{ft}$ measured for three times, and we record the minimum value. The criterion is adjusted according to gender and height. Men: height $\leq 173 \mathrm{~cm}$ and time $\geq 7 \mathrm{~s}$; height $>173 \mathrm{~cm}$ and time $\geq 6 \mathrm{~s}$. Women: height $\leq 159 \mathrm{~cm}$ and time $\geq 7 \mathrm{~s}$; height $>159 \mathrm{~cm}$ and time $\geq 6 \mathrm{~s}$, (5) weakness: weakness assessed by grip strength using a handgrip dynamometer was measured for three times, and we record the maximum value, adjusted for gender and BMI. Men: BMI $\leq 24$ and grip strength $\leq 29$ BMI 24.1-26 and 
grip strength $\leq 30$; BMI 26.1-28 and grip strength $\leq 30$; BMI $>28$ and grip strength $\leq 32$. Women:

BMI $\leq 23$ and grip strength $\leq 17$; BMI $23.1-26$ and grip strength $\leq 17.3$; BMI $26.1-29$ and grip strength $\leq 18$; BMI $>29$ and grip strength $\leq 21$.

\section{Dependent variables}

HRQoL was measured by the health utility value of EQ-5D-5L. ${ }^{38}$ The EQ-5D-5L consists of the EQ-5D-5L descriptive system and the EQ visual analogue scale. The EQ-5D-5L descriptive system has five elements (mobility, self-care, usual activities, pain/discomfort and anxiety/ depression) and each element includes five levels (no problems, some problems, moderate problems, severe problems and extreme problems). The latest EQ-5D-5L health utility score method refers to Chinese integral conversion table. ${ }^{38}$ The range of utility value is $(-0.391$, 1.000). A higher score indicates better health condition of the respondents. Cronbach's alpha was 0.761 in this study.

\section{Mediator}

Physical disability was evaluated by the Activity of Daily Living Scale (ADLS), which was developed by Lawton and Brody in 1969 to measure the disability of older adults. ${ }^{39}$ The Scale consists of 14 items, including Physical Self-Maintenance Scale and Instrumental Activities of Daily Living. The total score is $14-56$, with higher scores indicating increased physical disability. A score of 14 and lower indicates completely normal physical ability, a score between 15 and 22 is defined as mild disability and a score of 23 and higher is defined as severe disability. ADLS is recommended by WHO and has been widely used in older adults in China, with good reliability and validity. ${ }^{41}$ Cronbach's alpha was 0.764 in this study.

\section{Moderator}

PA was assessed using the IPAQ-SF. ${ }^{36}{ }^{37}$ The questionnaire contains seven questions, six of which were about PA. The IPAQ-SF investigates the PA of the individuals in the last 7 days. The questionnaire involved three types of intensity activities, including vigorous PA (8.0 metabolic equivalent (METs)), moderate PA (4.0 METs) and low PA (3.3 METs). PA of each person engaged in a certain intensity per week is the MET value corresponding to that PA $\times$ weekly frequency $\times$ daily time, and the sum of three PA is the total PA (met-hour/week). The greater the overall $\mathrm{PA}$ value, the higher the PA.

\section{Data analysis}

To analyse the data, categorical variables were expressed using frequency and percentages (\%) and continuous data were described using mean (SD). Spearman correlation coefficient was used to analyse the correlation among physical frailty, physical disability and HRQoL. All these analyses were performed using IBM SPSS V.24.0 (IBM, Armonk, New York, USA). All regression coefficients were tested by the bias-corrected percentile Bootstrap method. The theoretical model was tested by estimating the $95 \%$ CI for mediation and moderating effects with 5000 sampled with repetition. If the $95 \%$ CI did not include 0 , it meant that the statistics was significant. To illuminate the moderating effect, the moderated variable (PA) is divided into two levels of high and low according to one SD above and below the mean $(\mathrm{M}+1 \mathrm{SD} / \mathrm{M}-1 \mathrm{SD}) .{ }^{42-44}$ The splitplot analysis method was used to further examine the direction of the moderation effect and draw a diagram to explain the moderation effect. ${ }^{45}$ The mediation model and moderated mediation model were tested with the PROCESS V.3.3 macro for SPSS. ${ }^{46}$ In the current study, we selected model 4 and model 59 to analyse the mediating effect and moderated mediation effect. In addition, through t-test and analysis of variance (ANOVA) analysis, we found that HRQoL was related to age and education. Previous studies have also found that HRQoL was associated with age and education. ${ }^{47} 48$ We controlled age and education in this study. Sampling weights were used in all of the analyses to adjust for the survey design.

\section{Patient and public involvement statement}

This research was done without patient involvement. No patients were involved in developing the hypothesis and plans for design of this study either. The results would not be disseminated to study participants or any other individuals or communities.

\section{RESULTS}

\section{Common method biases}

We used Harman single factor test to conduct a common method biases test. ${ }^{49}$ The results show that there are 12 factors with eigenvalues greater than 1 , and the variance explained by the first factor is $17.92 \%$, which is less than $40 \%$ of the critical standard, indicating that there are no serious common method biases in this study.

\section{Sociodemographic characteristics of the participants}

There were 3243 participants, comprising 2060 (63.5\%) women and $1182(36.5 \%)$ men. The average age was $69.88(\mathrm{SD}=6.10)$ years, ranging from 60 to 97 years. Of the participants, $25.5 \%$ were single. About $72.4 \%$ had chronic disease. The majority $(81.9 \%)$ was empty nest elderly.

\section{Bivariate correlations of main variables}

The mean, $\mathrm{SD} /$ median (quartile $_{1}$, quartile $_{3}$ ) and correlation coefficient of each variable are shown in table 1 . Physical frailty was positively correlated with physical disability $(\rho=0.283, \mathrm{p}<0.01)$, physical frailty was negatively correlated with HRQoL $(\rho=-0.429, \mathrm{p}<0.01)$ and PA $(\rho=-0.378, \mathrm{p}<0.01)$. Physical disability was negatively correlated with HRQoL $(\rho=-0.378, \mathrm{p}<0.01)$ and PA $(\rho$ $=-0.194, \mathrm{p}<0.01)$. PA was positively correlated with HRQoL $(\rho=0.258, \mathrm{p}<0.01)$.

\section{Mediation effect analysis}

Model 4 in the SPSS macrocompiled by Hayes ${ }^{46}$ was used to test the mediating effect of physical disability in the 
Table 1 Spearman correlation coefficients of main variables among the participants in Shandong, China, 2019 (N=3243)

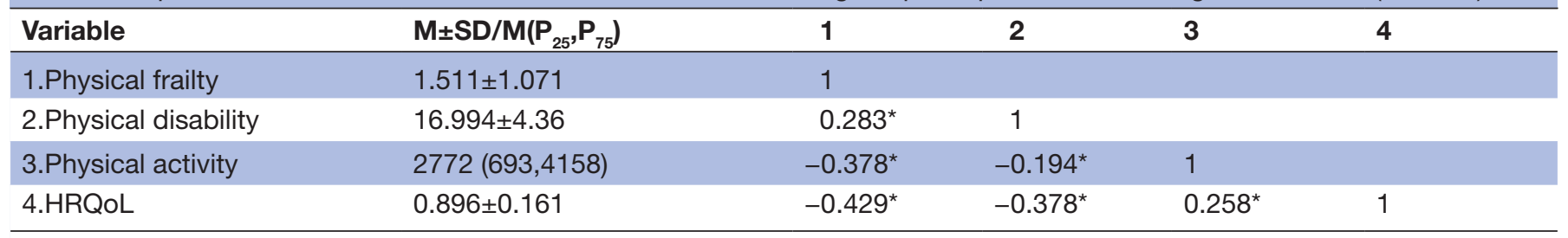

$\mathrm{M} \pm \mathrm{SD}$ : mean $\pm \mathrm{SD} ; \mathrm{M}(\mathrm{P} 25, \mathrm{P} 75)$ : median (quartile , quartile $_{3}$ ).

$1,2,4$ follow normal distribution and are described as $M \pm S D$.

3 does not follow normal distribution and is described as $M\left(P_{25}, P_{75}\right)$. ${ }^{*} \mathrm{p}<0.001$.

$\mathrm{HRQ}$ L, health-related quality of life.

relationship between physical frailty and HRQoL under the control variable of age, education. As shown in tables 2 and 3, physical frailty had a significant predictive effect on quality of life $(\beta=-0.423, t=-26.031, p<0.001)$, and the direct predictive effect of frailty on quality of life was still significant when the mediating variable physical disability was added. Meanwhile, physical frailty had a significant positive predictive effect on physical disability $(\beta=0.295, \mathrm{t}=17.729, \mathrm{p}<0.001)$. Physical disability also had a significant negative predictive effect on HRQoL $(\beta=-0.482, t=-32.407, p<0.001)$. In addition, the upper and lower limits of the bootstrap 95\% CI for the direct effect of physical frailty on HRQoL and the mediating effect of physical disability on physical frailty and HRQoL did not include 0 (table 3 ), indicating that the mediating effect was significant. The mediating effect value was -0.143 and the $95 \% \mathrm{CI}$ was $(-0.175$ to -0.113$)$, which accounted for $33.71 \%$ of the total effect. This showed that disability played a partial mediating role in the relationship between physical frailty and HRQoL.

\section{Moderated mediation effect analysis}

PROCESS macro method (model 59) compiled by Hayes and Andrew $^{46}$ was used to test the moderated mediation model while controlling for age and education (tables 4 and 5). After PA was put into the model, the interaction term between physical frailty and PA significantly predicted physical disability $(\beta=-0.120, t=-7.058, \mathrm{p}<0.001)$ (table 4, model 1), and the interaction term between physical disability and PA also had a significant predictive effect on HRQoL $(\beta=0.115, t=6.104, p<0.001)$. But the interaction term between physical frailty and PA had no effect on HRQoL (table 4, model 2). These results suggested that PA played a moderating role in the relationships between physical frailty and physical disability and between physical disability and HRQoL. However, PA did not significantly moderate the relationships between physical frailty and HRQoL. Simple slope analyses indicated that the significant interaction at $1 \mathrm{SD}$ below the mean (M-1SD) and $1 \mathrm{SD}$ above the mean $(\mathrm{M}+1 \mathrm{SD})$ of PA (see figures 2 and 3). Physical frailty had a significant predictive effect on the disability of individuals with high-level $(\mathrm{M}+1 \mathrm{SD})$ or low-level (M-1SD) PA, but the predictive effect of physical frailty on physical disability was stronger for individuals with low-level PA $\left(\mathrm{b}_{\text {simple }}=0.370, \mathrm{t}=16.979, \mathrm{p}<0.001\right)$ than for individuals with high-level PA, as shown in figure 2 $\left(b_{\text {simple }}=0.120, \mathrm{t}=4.322, \mathrm{p}<0.001\right)$. Figure 3 shows that for high levels of PA individuals, the effect of physical disability and HRQoL was significant $\left(b_{\text {simple }}=-0.304, t=-9.149\right.$, $\mathrm{p}<0.001)$. However, for low-level of PA individuals, the effect of physical disability and HRQoL was still significant but considerably stronger $\left(\mathrm{b}_{\text {simple }}=-0.543, \mathrm{t}=-28.654\right.$, $\mathrm{p}<0.001$ ). In addition, as the level of PA increased, the mediating effect of physical disability on the relationship between physical frailty and HRQoL declined (table 5).

Table 2 Testing the mediation effect of physical disability between physical frailty and HRQL among the participants in Shandong, China, 2019

\begin{tabular}{|c|c|c|c|c|c|c|}
\hline \multirow[b]{2}{*}{ Predictors } & \multicolumn{2}{|c|}{ Model 1 (HRQoL) } & \multicolumn{2}{|c|}{ Model 2 (physical disability) } & \multicolumn{2}{|c|}{ Model 3 (HQRoL) } \\
\hline & $\boldsymbol{\beta}$ & $\mathbf{t}$ & $\boldsymbol{\beta}$ & $\mathbf{t}$ & $\boldsymbol{\beta}$ & $\mathbf{t}$ \\
\hline Age & -0.018 & -0.731 & 0.166 & $6.349^{\star \star}$ & 0.061 & $2.758^{\star}$ \\
\hline Physical frailty & -0.423 & $-26.031^{\star \star}$ & 0.295 & $17.729^{\star \star}$ & -0.280 & $-18.957^{\star *}$ \\
\hline Physical disability & & & & & -0.482 & $-32.407^{\star \star}$ \\
\hline
\end{tabular}

${ }^{*} \mathrm{p}<0.01,{ }^{* \star} \mathrm{p}<0.001$.

$\mathrm{HRQ}$ oL, health-related quality of life. 
Table 3 Total effect, direct effect and mediation effect

\begin{tabular}{llllll} 
& & & BootCl & & Relative effect \\
\cline { 4 - 5 } & Effect size & BootSE & Low & High & -0.382 \\
votal effect & -0.423 & 0.020 & -0.461 & -0.247 & $66.29 \%$ \\
Direct effect & -0.280 & 0.017 & -0.313 & -0.113 & $33.71 \%$ \\
Indirect effect & -0.143 & 0.016 & -0.175 & & \\
\hline
\end{tabular}

BootCl, bootstrap Cl; BootSE, bootstrap standard error.

\section{DISCUSSION}

In this study, a moderated mediation model was established with the mediation role of physical disability on the relationship between physical frailty and HRQoL as well as the role of PA as a moderator in this indirect path between physical frailty and HRQoL. These findings preliminarily elucidate the potential causes of physical frailty on HRQoL and facilitate the development of targeted interventions for individuals so as to improve HRQoL in rural older adults.

Consistent with previous studies, ${ }^{50} 51$ we find that physical frailty has a negative association with HRQoL. This suggests that as the degree of physical frailty increases, the quality of life in older adults becomes worse. Although many studies have established a direct relationship between frailty and HRQoL, few have explored the underlying mechanisms of this relationship. Our study suggests that physical disability mediates the association between physical frailty and HRQoL, with the mediating rate of $33.71 \%$. A study also suggested that physical disability was one of the potential factors underlying the association between frailty and HRQoL, which was similar with our study. ${ }^{52}$

The current study indicates that physical frailty is associated with disability, which is consistent with a study by Kojuma. ${ }^{53}$ Frail older adults are very vulnerable to adverse health effects. A study indicated that the risk of disability in frail older adults was 12-fold to 13-fold increased than that in non-frail older adults. ${ }^{54}$ Meanwhile, this study also demonstrates a negative predictive effect of disability on individual HRQoL, which was consistent with previous studies. ${ }^{556}$ The possible explanation is that disabled older adults' poor self-care ability deteriorates their health, then their normal physiological activities are restricted, physiological function is declined and social interaction is reduced, which adversely affect their physical and mental health and ultimately reduce HRQoL. One study found that disability was the most important health problem for older adults, which seriously affected their quality of life in old adults' later years. ${ }^{57}$ The disability was the most important factor that contributed to decreasing quality of life in older adults. Physical disability has been proved to be associated with increased chronic diseases, and premature mortality ${ }^{58} 59$ all of which could adversely affect the quality of life of older adults. ${ }^{60}$ Therefore, physical frailty may reduce HRQoL of rural older adults by increasing their disability.

In the present study, we also find that PA appears to play a moderating role in the indirect effect between physical frailty and HRQoL. A larger indirect effect is observed among rural older adults with low level of PA than among those with average or high level of PA. Specifically, PA appears to moderate the relationship between physical frailty and physical disability and between physical disability and HRQoL. For older adults with low-level PA, the impact of physical frailty on physical disability

Table 4 Testing the moderated mediation effect of physical frailty on HRQoL among the participants in Shandong, China, 2019

\begin{tabular}{|c|c|c|c|c|}
\hline \multirow[b]{2}{*}{ Predictors } & \multicolumn{2}{|c|}{ Model 1(physical disability) } & \multicolumn{2}{|c|}{ Model 2 (HRQoL) } \\
\hline & $\boldsymbol{\beta}$ & $\mathbf{t}$ & $\beta$ & $\mathbf{t}$ \\
\hline Age & 0.154 & $5.956^{\star *}$ & 0.062 & $2.763^{*}$ \\
\hline Education & -0.181 & $-8.393^{\star \star}$ & -0.072 & $-3.830^{\star *}$ \\
\hline Physical frailty & 0.246 & $13.965^{\star \star}$ & -0.258 & $-16.687^{\star \star}$ \\
\hline Physical activity & -0.104 & $-5.555^{\star \star}$ & 0.091 & $4.675^{\star \star}$ \\
\hline Physical frailty $\times$ PA & -0.120 & $-7.058^{\star \star}$ & 0.011 & 0.682 \\
\hline Physical disability & & & -0.422 & $-24.375^{\star \star}$ \\
\hline Physical disability $\times$ PA & & & 0.115 & $6.104^{* *}$ \\
\hline $\mathrm{R}^{2}$ & 0.159 & & 0.390 & \\
\hline $\mathrm{F}$ & $122.004^{\star \star}$ & & $295.850^{\star *}$ & \\
\hline
\end{tabular}

${ }^{*} p<0.01,{ }^{* *} p<0.001$.

HRQoL, health-related quality of life; PA, physical activity. 
Table 5 Mediating effect values at different levels of physical activity among the participants in Shandong, China, 2019

\begin{tabular}{lllll}
\hline Physical activity & Effect & BootSE & BootLLCI & BootULCI \\
\hline M-1SD (low level) & -0.201 & 0.023 & -0.250 & -0.160 \\
M & -0.104 & 0.013 & -0.131 & -0.080 \\
M+1SD (high level) & -0.036 & 0.012 & -0.062 & -0.017 \\
\hline
\end{tabular}

BootLLCI, bootstrap lower limit Cl; BootSE, bootstrap SE; BootULCI, bootstrap upper limit Cl; 1SD, one SD.

is stronger than older adults with high-level PA. This finding indicates that PA appears to moderate the relationship between physical frailty and physical disability. We speculate that older adults with low-level PA may have a decline in their physiological system reserves, leading to a deterioration of their functional status and ultimately increasing the possibility of physical frailty and disability. ${ }^{61}$ A systematic review showed that older adults without exercise habits were at greater risk of developing frailty. Taichi, resistance sports and other physical activities might effectively improve the health of older adults, reduce the symptoms of physical weakness and prevent the occurrence of physical disability ${ }^{62}$ Compared with older adults with high-level PA, older adults with low-level PA are more vulnerable to the negative effects of physical frailty. As a result, physical frailty may cause more interference in older adults with low-level PA and increase the risk of physical disability.

We also find that physical disability has a significant impact on quality of life at both high-level and low-level of PA. Compared with older adults with high levels of PA, physical disability is more likely to adversely affect HRQoL of older adults with low-level PA. A study showed that low-level PA was a major contributing factor for older adults' disability. ${ }^{63}$ As the level of disability increases, the individuals with low level of PA experience a more serious functional decline and become more worried about the health status, thus further negatively affect the HRQoL. ${ }^{64}$ In addition, physical disability has a greater effect on individuals with low-level PA than high-level PA, which

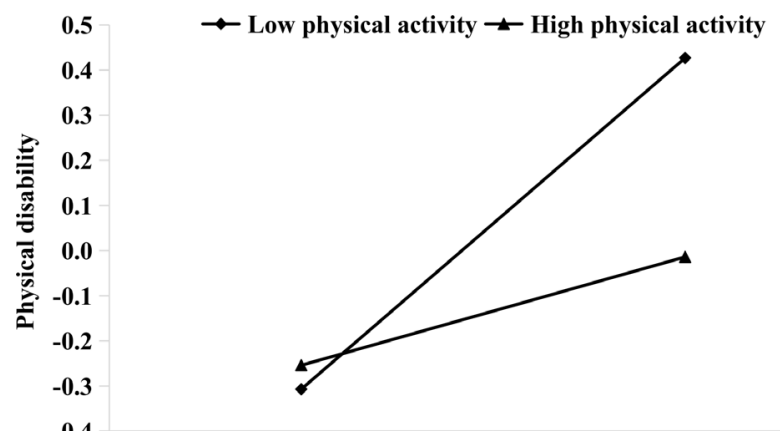

$$
\text { Low physical frailty High physical frailty }
$$

Figure 2 Simple slope analysis shows that physical frailty moderated the relationship between physical frailty and physical disability.

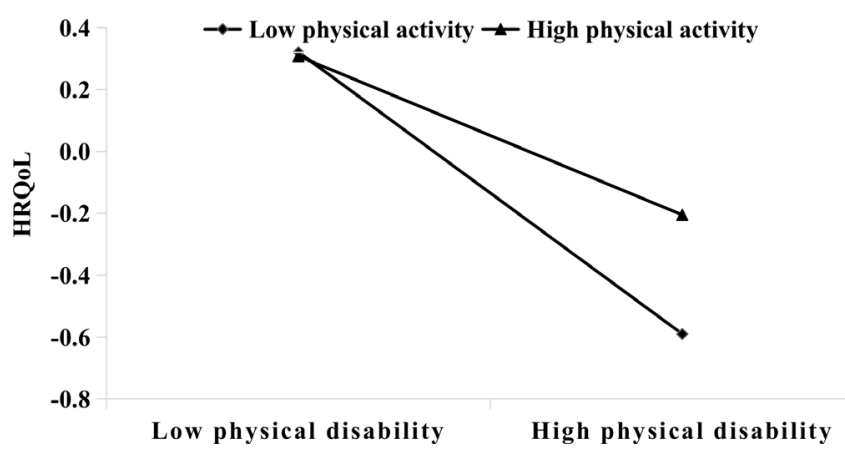

Figure 3 Simple slope analysis shows that physical activity moderated the relationship between physical disability and HRQoL. HRQoL, health-related quality of life.

indicates that PA plays a moderating role between physical disability and HRQoL. One study found that PA could improve the physical function and daily life activities of disabled older adults and ultimately improved the life of older adults quality ${ }^{65}$ Therefore, a low level of PA might be associated with poor quality of life in rural older adults with high disability.

However, PA does not appear to moderate the direct relationship between physical frailty and HRQoL. Physical frailty may lead to a decline in physical function, muscle strength and PA in older adults, which may increase the risk of adverse health outcomes and ultimately affect HRQoL of older adults. Currently, there are few studies on the moderating role of PA between physical frailty and HRQoL. Further research is needed to explore the underlying reasons for such findings.

Based on our findings, we recommend that community health managers should focus on ensuring the medical assistance, life care of older adults with physical frailty or physical disability. Besides, rural communities should establish some public facilities or organise some public activities to encourage older adults to participate in sports activities and ultimately improve health and promote their HRQoL. There are several limitations in this study. First, our study was based on a cross-sectional study, which could not provide strong evidence of causation. In addition, using cross-sectional data to examine longitudinal mediation effects can lead to biased estimates of mediation effects. ${ }^{66}$ Future research could adopt a longitudinal design or experiments to explore the causal relationship between physical frailty and HRQoL. Second, the data in this study come from the participants' self-reported information, which might result in recall bias. Third, this study only included age and education as control variables. The study may also be affected by other confounding factors. In the future, we will include more confounding factors related to quality of life to verify our findings. Fourthly, physical disability has a partly mediating effect on the relationship between physical frailty and HRQoL, which indicates that there are other mediating variables in this relationship. More potential mechanisms related to the association between physical frailty and HRQoL among older adults need to be explored in the future. 


\section{CONCLUSION}

This study shows that physical frailty is related to HRQoL, and physical disability appears to mediate the relationship between physical frailty and HRQoL, and PA appears to moderate the mediating relationship. A greater effect is observed among rural older adults with low level of PA than that among those with high level of PA. This provides support for elucidate the underlying mechanism of the relationship between physical frailty and HRQoL and form an effective way to improve the HRQoL of older adults in rural areas.

Acknowledgements We thank the officials of health agencies, all participants and staffs at the study sites for their cooperation.

Contributors Study concept and design: $\mathrm{CZ}$ and WH. Acquisition of data: DZ, $\mathrm{CY}$ and YY. Analysis and interpretation of data: PF, ZJ and YW. Drafting of the manuscript: WH. Critical revision of the manuscript for important intellectual content: CZ and JL. All authors read and approved the final manuscript.

Funding This study was supported by the National Natural Science Foundation of China (71774104, 71473152, 71974117), the China Medical Board (16-257), Cheeloo Youth Scholar Grant, Shandong University (IFYT1810,2012DX006) and NHC Key Laboratory of Health Economics and Policy Research (NHC-HEPR2019014).

Competing interests None declared.

Patient consent for publication Not required.

Ethics approval The study was approved by the Ethics Committee of School of Public Health in Shandong University, P. R. China. The participants have been informed of the purpose and procedures of the study before the investigation. Before the study began, participants had signed written informed consent indicating that they were fully aware of the study procedures.

Provenance and peer review Not commissioned; externally peer reviewed.

Data availability statement The data that support the findings of this study are available from the corresponding author upon reasonable request.

Open access This is an open access article distributed in accordance with the Creative Commons Attribution Non Commercial (CC BY-NC 4.0) license, which permits others to distribute, remix, adapt, build upon this work non-commercially, and license their derivative works on different terms, provided the original work is properly cited, appropriate credit is given, any changes made indicated, and the use is non-commercial. See: http://creativecommons.org/licenses/by-nc/4.0/.

\section{ORCID iDs}

Wenting Hao http://orcid.org/0000-0001-5972-6357

Caiting Yu http://orcid.org/0000-0002-7296-8593

Chengchao Zhou http://orcid.org/0000-0002-9364-3579

\section{REFERENCES}

1 NBSC. Statistical communiqué of the People's Republic of China on the 2017 national economic and social development, 2017. Available: http://www.stats.gov.cn/english/PressRelease/201802/t20180228_ 1585666.html

2 United Nations DESA, Population Division. World population ageing 2017: Highlights, 2017. Available: https://www.un.org/en/ development/desa/population/publications/pdf/ageing/WPA2017_ Highlights.pdf

3 Brown DS, Thompson WW, Zack MM, et al. Associations between health-related quality of life and mortality in older adults. Prev Sci 2015;16:21-30.

4 Zhou B, Chen K, Wang J, et al. Quality of life and related factors in the older rural and urban Chinese populations in Zhejiang Province. $J$ Appl Gerontol 2011;30:199-225.

5 Zhou Z, Zhou Z, Gao J, et al. Urban-Rural difference in the associations between living arrangements and the health-related quality of life (HRQOL) of the elderly in China-Evidence from Shaanxi Province. PLoS One 2018;13:e0204118.

6 Morley JE, Vellas B, van Kan GA, et al. Frailty consensus: a call to action. J Am Med Dir Assoc 2013;14:392-7.
7 Collard RM, Boter H, Schoevers RA, et al. Prevalence of frailty in community-dwelling older persons: a systematic review. J Am Geriatr Soc 2012;60:1487-92.

8 Vermeiren S, Vella-Azzopardi R, Beckwée D, et al. Frailty and the prediction of negative health outcomes: a meta-analysis. J Am Med Dir Assoc 2016;17:1163.e1-1163.e17.

9 Lee I-C, Chiu Y-H, Lee C-Y. Exploration of the importance of geriatric frailty on health-related quality of life. Psychogeriatrics 2016;16:368-75.

10 Ferrer A, Formiga F, Cunillera O, et al. Predicting factors of healthrelated quality of life in octogenarians: a 3-year follow-up longitudinal study. Qual Life Res 2015;24:2701-11.

11 Provencher V, Sirois M-J, Émond M, et al. Frail older adults with minor fractures show lower health-related quality of life (SF-12) scores up to six months following emergency department discharge. Health Qual Life Outcomes 2016;14:40.

12 Kanauchi M, Kubo A, Kanauchi K, et al. Frailty, health-related quality of life and mental well-being in older adults with cardiometabolic risk factors. Int J Clin Pract 2008;62:1447-51.

13 Fuller-Thomson E, Yu B, Nuru-Jeter A, et al. Basic ADL disability and functional limitation rates among older Americans from 2000-2005: the end of the decline? J Gerontol A Biol Sci Med Sci 2009;64:1333-6.

14 Picavet HSJ, Hoeymans N. Physical disability in the Netherlands: prevalence, risk groups and time trends. Public Health 2002;116:231-7.

15 Evenhuis HM, Hermans H, Hilgenkamp TIM, et al. Frailty and disability in older adults with intellectual disabilities: results from the healthy ageing and intellectual disability study. J Am Geriatr Soc 2012;60:934-8.

16 Dent E, Chapman I, Howell S, et al. Frailty and functional decline indices predict poor outcomes in hospitalised older people. Age Ageing 2014;43:477-84.

17 Papachristou E, Wannamethee SG, Lennon LT, et al. Ability of selfreported frailty components to predict incident disability, falls, and all-cause mortality: results from a population-based study of older British men. J Am Med Dir Assoc 2017;18:152-7.

18 Bandeen-Roche K, Seplaki CL, Huang J, et al. Frailty in older adults: a nationally representative profile in the United States. $J$ Gerontol $A$ Biol Sci Med Sci 2015;70:1427-34.

19 Makizako H, Shimada H, Doi T, et al. Impact of physical frailty on disability in community-dwelling older adults: a prospective cohort study. BMJ Open 2015;5:e008462.

20 Medhi GK, Sarma J, Pala S, et al. Association between health related quality of life (HRQOL) and activity of daily living (ADL) among elderly in an urban setting of Assam, India. J Family Med Prim Care 2019;8:1760-4.

21 Tavassoli N, Guyonnet S, Abellan Van Kan G. Description of 1,108 older patients referred by their physician to the "Geriatric Frailty Clinic (G. F.C) for Assessment of Frailty and Prevention of Disability" at the gerontopole. J Nutr Health Aging 2014;18:457-64.

22 Viña J, Salvador-Pascual A, Tarazona-Santabalbina FJ, et al. Exercise training as a drug to treat age associated frailty. Free Radic Biol Med 2016;98:159-64.

23 Rector JL, Marceau K, Friedman EM. Moderation of the association between chronic medical conditions and functional limitations over time by physical activity: effects of age. J Gerontol A Biol Sci Med Sci 2020;75:168-74.

24 Palmer RF, Espino DV, Dergance JM, et al. The role of physical activity and diabetes status as a moderator: functional disability among older Mexican Americans. Age Ageing 2012;41:752-8.

25 Keysor JJ. Does late-life physical activity or exercise prevent or minimize disablement? A critical review of the scientific evidence. Am J Prev Med 2003;25:129-36.

26 Keysor JJ, Jette AM. Have we oversold the benefit of late-life exercise? J Gerontol A Biol Sci Med Sci 2001;56:M412-23.

27 Rejeski WJ, Mihalko SL. Physical activity and quality of life in older adults. J Gerontol A Biol Sci Med Sci 2001;56 Spec No 2:23-35.

28 Casas-Herrero A, Izquierdo M. [Physical exercise as an efficient intervention in frail elderly persons]. An Sist Sanit Navar 2012;35:69-85

29 Mañas A, Del Pozo-Cruz B, Guadalupe-Grau A, et al. Reallocating Accelerometer-Assessed sedentary time to light or moderate- to Vigorous-Intensity physical activity reduces frailty levels in older adults: an Isotemporal substitution approach in the TSHA study. $J$ Am Med Dir Assoc 2018;19:185.e1-185.e6.

30 Barnett A, Smith B, Lord SR, et al. Community-Based group exercise improves balance and reduces falls in at-risk older people: a randomised controlled trial. Age Ageing 2003;32:407-14.

31 Jing Z, Li J, Wang Y, et al. The mediating effect of psychological distress on cognitive function and physical frailty among the 
elderly: evidence from rural Shandong, China. $J$ Affect Disord 2020;268:88-94.

32 Fried LP, Tangen CM, Walston J, et al. Frailty in older adults: evidence for a phenotype. J Gerontol A Biol Sci Med Sci 2001;56:M146-57.

33 Buta BJ, Walston JD, Godino JG, et al. Frailty assessment instruments: systematic characterization of the uses and contexts of highly-cited instruments. Ageing Res Rev 2016;26:53-61.

34 Bouillon K, Kivimaki M, Hamer M, et al. Measures of frailty in population-based studies: an overview. BMC Geriatr 2013;13:64

35 Radloff LS. The CES-D scale a self-report depression scale for research in the general population. Appl Psychol Meas 1977;1:385-401.

36 Fan M, Lyu J, He P. [Chinese guidelines for data processing and analysis concerning the International Physical Activity Questionnaire] Zhonghua Liu Xing Bing Xue Za Zhi 2014;35:961-4.

37 Macfarlane DJ, Lee CCY, Ho EYK, et al. Reliability and validity of the Chinese version of IPAQ (short, last 7 days). J Sci Med Sport $2007 ; 10: 45-51$

38 Luo N, Liu G, Li M, et al. Estimating an EQ-5D-5L value set for China. Value Health 2017;20:662-9.

39 Lawton MP, Brody EM. Assessment of older people: selfmaintaining and instrumental activities of daily living. Gerontologist 1969;9:179-86.

40 Lawton MP. The functional assessment of elderly people. J Am Geriatr Soc 1971:19:465-81.

41 Chen P, Yu ES, Zhang M, et al. ADL dependence and medical conditions in Chinese older persons: a population-based survey in Shanghai, China. J Am Geriatr Soc 1995;43:378-83.

$42 \mathrm{Ng} \mathrm{K}-\mathrm{Y}$, Ang S, Chan K-Y. Personality and leader effectiveness: a moderated mediation model of leadership self-efficacy, job demands, and job autonomy. J Appl Psychol 2008;93:733-43.

43 Preacher KJ, Rucker DD, Hayes AF. Addressing moderated mediation hypotheses: theory, methods, and prescriptions. Multivariate Behav Res 2007;42:185-227.

44 Holmbeck GN. Toward Terminological, conceptual, and statistical clarity in the study of mediators and moderators: examples from the child-clinical and pediatric psychology literatures. J Consult Clin Psychol 1997;65:599-610.

45 Cohen J, Cohen P, West SG. Applied multiple regression/correlation analysis for the behavioral sciences. Routledge, 2013.

46 Hayes BJH, Andrew F. Introduction to mediation, moderation, and conditional process analysis: a regression-based approach. New York, NY: the Guilford press. J Educ Meas 2014 2013;51:335-7.

47 Bao X-Y, Xie Y-X, Zhang X-X, et al. The association between multimorbidity and health-related quality of life: a cross-sectional survey among community middle-aged and elderly residents in southern China. Health Qual Life Outcomes 2019:17:107.

48 Chapman B, Duberstein P, Lyness JM. Personality traits, education, and health-related quality of life among older adult primary care patients. J Gerontol B Psychol Sci Soc Sci 2007;62:P343-52.

49 Podsakoff PM, MacKenzie SB, Lee J-Y, et al. Common method biases in behavioral research: a critical review of the literature and recommended remedies. J Appl Psychol 2003;88:879-903.
50 Kanwar A, Singh M, Lennon R, et al. Frailty and health-related quality of life among residents of long-term care facilities. J Aging Health 2013;25:792-802.

51 Mulasso A, Roppolo M, Rabaglietti E. The role of individual characteristics and physical frailty on health related quality of life (HRQOL): a cross sectional study of Italian community-dwelling older adults. Arch Gerontol Geriatr 2014;59:542-8.

52 Huaxue L, Taifang L, Wenjing Y. Status of frailty and its effect path on quality of life among the elderly in community. Chinese Nursing Research 2019;33:3645-9.

53 Kojima G. Frailty as a predictor of disabilities among communitydwelling older people: a systematic review and meta-analysis. Disabil Rehabil 2017;39:1897-908.

54 Feng L, Zin Nyunt MS, Gao Q, et al. Cognitive frailty and adverse health outcomes: findings from the Singapore longitudinal ageing studies (SLAS). J Am Med Dir Assoc 2017;18:252-8.

55 Akosile CO, Mgbeojedo UG, Maruf FA, et al. Depression, functional disability and quality of life among Nigerian older adults: prevalences and relationships. Arch Gerontol Geriatr 2018;74:39-43.

56 Shin KR, Byeon YS, Kang Y, et al. [A study on physical symptom, activity of daily living, and health-related quality of life (HRQoL) in the community-dwelling older adults]. Taehan Kanho Hakhoe Chi 2008;38:437-44.

57 Crimmins EM. Trends in the health of the elderly. Annu Rev Public Health 2004;25:79-98.

58 Khan ZA, Singh C, Khan T. Correlates of physical disability in the elderly population of rural North India (Haryana). J Family Community Med 2018;25:199-204.

59 Wei M, Li J, Wang H. Impact of the disability trajectory on the mortality risk of older adults in China. Arch Gerontol Geriatr 2018;74:174-83.

60 Gobbens RJ. Associations of ADL and IADL disability with physical and mental dimensions of quality of life in people aged 75 years and older. PeerJ 2018;6:e5425.

61 Rejeski WJ, Brawley LR, Haskell WL. The prevention challenge: an overview of this supplement. Am J Prev Med 2003;25:107-9.

62 de Labra C, Guimaraes-Pinheiro C, Maseda A, et al. Effects of physical exercise interventions in frail older adults: a systematic review of randomized controlled trials. BMC Geriatr 2015;15:154.

63 Kortebein P, Ferrando A, Lombeida J, et al. Effect of 10 days of bed rest on skeletal muscle in healthy older adults. JAMA 2007;297:1769-4.

64 Ávila-Funes JA, Pina-Escudero SD, Aguilar-Navarro S, et al. Cognitive impairment and low physical activity are the components of frailty more strongly associated with disability. J Nutr Health Aging 2011;15:683-9.

65 Villareal DT, Chode S, Parimi N, et al. Weight loss, exercise, or both and physical function in obese older adults. $N$ Engl $J$ Med 2011;364:1218-29.

66 Maxwell SE, Cole DA, Mitchell MA. Bias in cross-sectional analyses of longitudinal mediation: partial and complete mediation under an autoregressive model. Multivariate Behav Res 2011;46:816-41. 